\title{
VASER-Assisted Short-Scar Brachioplasty in Post-Massive Weight Loss Patients
}

\author{
SOHA F. EL-MEKKAWY, M.D.
}

The Department of Plastic and Reconstructive Surgery, Faculty of Medicine, Ain Shams University, Egypt

\begin{abstract}
Background: Brachioplasty has been performed for several decades, became more frequent again with the advent of bariatric surgery, however, it has a huge disadvantage which is the unsatisfactory appearance of the long surgical scar.

Patients and Methods: We performed transaxillary shortscar VASER-assisted brachioplasty for 14 patients complaining of cosmetic disfigurement of their arms after considerable weight loss. Post-operative complications and patients' satisfaction were obtained and analyzed.

Results: Complications rates were 21.4 percent. Evaluation reported overall satisfaction; excellent for 13 patients; good for 1 and no patients reported poor results. No revision surgery was needed.

Conclusion: Transaxillary VASER-assisted brachioplasty is an easy and simple technique that offers a good result with the most possible minimal scarring.
\end{abstract}

Key Words: VASER - Brachioplasty - Weight loss.

\section{INTRODUCTION}

Brachioplasty, which has been performed for several decades. Many procedures were described since the 30's. The main side-effect of brachioplasty is the long apparent scar that usually affect both patients and surgeons' overall satisfaction [1].

To overcome this; superficial liposuction only was proposed to be an alternative method. This served to achieve good results with minimal scarring; however its usage was restricted to those with minimal skin laxity [2].

In another rationale, many authors had used liposuction as an adjuvant to the short-scar brachioplasty to treat more distal deformities of the arm. Although higher patients' satisfaction was produced, but again this was limited to those with moderately skin laxity that is located proximally only and not the entire arm [3].
VASER assisted lipoplasty (VAL) is the third generation of ultrasonic instrumentation for lipoplasty. This technique combines advances in energy delivery with enhanced clinical techniques to manipulate fatty tissues [4].

VASER concept is based on emission of pulsed or continuous ultrasound energy to emulsify fat before its aspiration. If compared with previous ultrasonic assisted liposuction machines, it focus on the safety and efficiency of the process as it preserves vessels and nerves and causes less pain and hematomas [5].

Since its introduction, VAL has been widely used in combination to excisional surgery for body re-shaping to decrease complication rates with a better appealing result. This might not be achieved in huge weight loss patients who typically have poor tone and thus many authors believe that these types of are not ideal candidates for this approach.

In this study we aim to increase the range of use of transaxillary short-scar brachioplasty accompanied by circumferential VASER liposuction to be used in massive weight-loss patients with moderately skin laxity with or without moderate fat deposits in the entire arm.

\section{PATIENTS AND METHODS}

The present study was conducted between June 2014 and June 2016. It included fourteen patients having cosmetic disfigurement of their arms after massive weight loss in the form of moderate skin excess of the entire arms with either minimal or moderate fat excess i.e. type IIb and IIIb according to an algorithmic approach to upper arm reshaping (Table 1) [6]. 
Table (1): Upper arm deformity classification.

\begin{tabular}{lclc}
\hline Type & Skin Excess & Fat Excess & Location of Skin Excess \\
\hline I & Minimal & Moderate & - \\
IIa & Moderate & Minimal & Proximal \\
IIb & Moderate & Minimal & Entire arm \\
IIc & Moderate & Minimal & Arm and chest \\
IIIa & Moderate & Moderate & Proximal \\
IIIb & Moderate & Moderate & Entire arm \\
IIIc & Moderate & Moderate & Arm and chest \\
\hline
\end{tabular}

(Appelt et al., 2006) [4].

Patients aged above 50 years, BMI above 40 $\mathrm{kg} / \mathrm{m}^{2}$, patients having chronic illness as DM or hypertension were excluded from the study. An informed written consent was taken from each patient according to the regulations of the local research esthetic committee.

\section{Preoperative planning and markings:}

- Clinical examination of both arms to assess the extent of adiposity \& skin excess of arms, axilla, lateral chest and estimating the most hanging center. In addition we examined; the posterior axillary fold winging and anterior axillary fold descent.

- With the patient in the up-right position and arms adducted; the apparent ends of the anterior and posterior axillary folds are marked.

- Arm is then abducted; incision line is marked in the axillary crease in-between the axillary fold marks.

- Arm is abducted $90^{\circ}$; excess skin of the triceps area is pulled towards axillary crease and then area to be excised is marked.

- Marking of the liposuction areas (Circumferential distal $1 / 2$ of arm in all cases with liposuction of triceps area in 7 patients and deltoid area in 10 patients.

\section{Surgical technique:}

- General anesthesia in 11 patients and Local anesthesia with light sedation in 3 patients.

- Infiltration of super wet tumescence solution.

- Emulsification was performed using VASER liposuction system in continuous mode starting from deeper layers then progressed to superficial layers and liposuction of all desired areas using $4 \mathrm{~mm}$ cannulas was done.

- Incision was then done, dissection distally above the superficial fascia followed by excision and hemostasis.

- Anchoring the meridian in the axillary fascia.

- Closure of subcutaneous layer and the skin with 3/0 monofilament absorbable suture.

\section{Postoperative care:}

The patients received medical treatment in the form of antibiotics, anti-edematous and pain killer with a pressure garment applied to the arm for 2 weeks. The patients were examined periodically in follow-up period that ranged in-between 2 and 9 months (mean 6.5 \pm 2.6 ).

\section{Evaluation:}

Preoperative and postoperative digital pictures were taken at least one month after operation and every six months using Nikon-Coolpix-P500 Camera (12.1Mpx, 36X optical zoom). Data were evaluated using the chi-square test, independent $t$-test, logistic regression, and Pearson's coefficient. Significance was assessed at $p<0.05$.

Subjective evaluation was done by patient satisfaction assessment for the final result depending on the scar and of arms in correlation to the preoperative ones. Patient satisfaction was ranked on scale of 03 with 0 being no improvement and 3 being highly satisfied.

Objective evaluation was done by assessment of the outcome of surgery 1 and 6 months postoperatively by comparing the pre- and post-operative photos as regards the final aesthetic outcome by 2 plastic physicians, who were not involved in the treatment, were asked to act as evaluaters to give scores for the 20 cases. Their evaluation was recorded as percentage on a quartile grading scale: $<25 \%$ : Poor, 25-50\%: Moderate, 51-75\%: Good and 76100\%: Excellent result.

\section{RESULTS}

This study involved 14 women with an average age of 40 years (range, 24 to 48 years). All patients experienced post-massive weight loss cosmetic disfigurement of their arms. Ten cases were Appelt grade IIB and the remaining four patients were of grade III. In all cases, transaxillary short scar brachioplasty was done accompanied with the use Vaser lipolysis system and skin tightening mode (Figs. 1,2).

The overall complication rate was $21.4 \%(n=3)$. The complications encountered were superficial dehiscence at the center of the incision line in one case $(7.1 \%)$, scar widening in another case $(7.1 \%)$ and hypertrophic scarring in a third case (7.1\%). Otherwise, all patients showed uneventful postoperative period.

Subjective evaluation revealed overall high grade of satisfaction in 13 cases (Table 2). 
Objective evaluation of the final aesthetic outcome was very good in 13 cases (93\%). Only 1

Table (2): Subjective satisfaction in the studied cases.

\begin{tabular}{lcccc}
\hline & Frequency & Percent & $\begin{array}{c}\text { Valid } \\
\text { Percent }\end{array}$ & $\begin{array}{c}\text { Cumulative } \\
\text { Percent }\end{array}$ \\
\hline $\begin{array}{l}\text { Valid: } \\
\quad \text { Moderate } \\
\quad \text { Satisfaction }\end{array}$ & 1 & 7.1 & 7.1 & 7.1 \\
$\begin{array}{l}\text { High } \\
\text { Satisfaction }\end{array}$ & 13 & 92.9 & 92.9 & 100.0 \\
\hline Total & 14 & 100.0 & 100.0 & \\
\hline
\end{tabular}

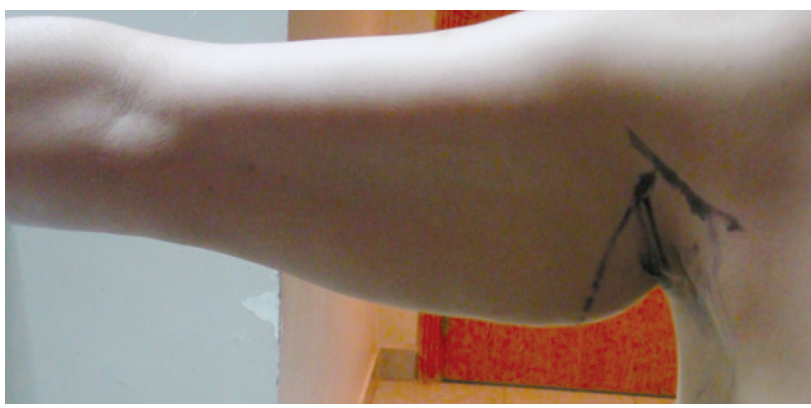

(A) case $(7.1 \%)$ reported residual skin laxity at the distal arm as presented in Table (3).

Table (3): Final aesthetic outcome.

\begin{tabular}{lcccc}
\hline & Frequency & Percent & $\begin{array}{c}\text { Valid } \\
\text { Percent }\end{array}$ & $\begin{array}{c}\text { Cumulative } \\
\text { Percent }\end{array}$ \\
\hline $\begin{array}{l}\text { Valid: } \\
\text { Good } \\
\quad[51 \%-75 \%]\end{array}$ & 1 & 7.1 & 7.1 & 7.1 \\
$\begin{array}{c}\text { Excellent } \\
{[76 \%-100 \%]}\end{array}$ & 13 & 92.9 & 92.9 & 100.0 \\
\hline Total & 14 & 100.0 & 100.0 & \\
\hline
\end{tabular}

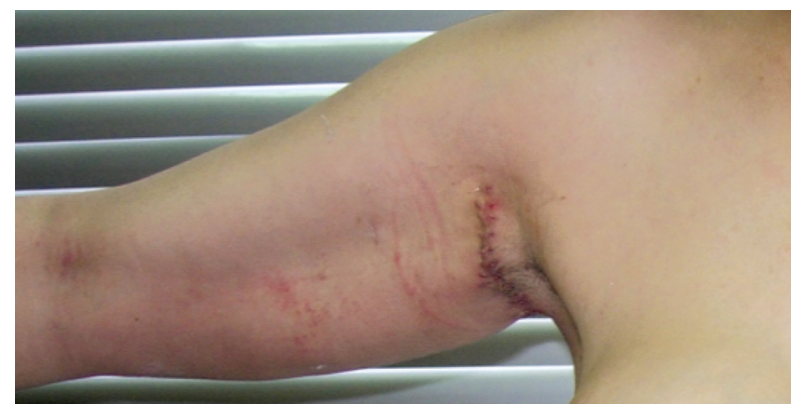

(B)

Fig. (1): Preoperative (a) and Postoperative (b) Photos of a 32 years old female with type IIb arm deformity

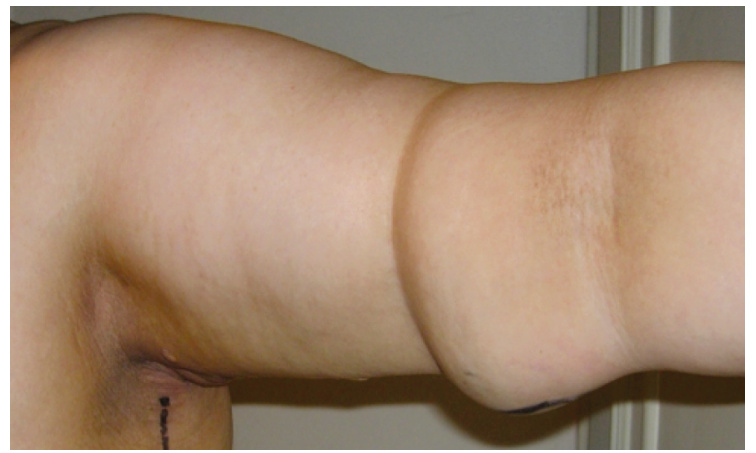

(A)

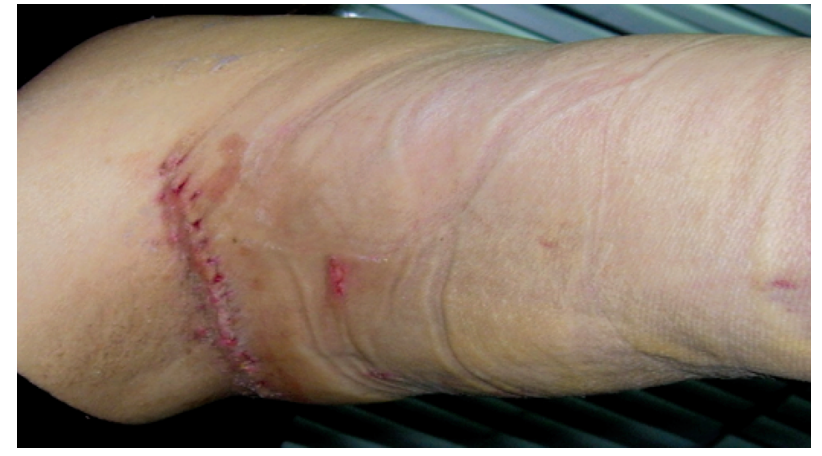

(B)

Fig. (2): Preoperative (left) and postoperative (right) photos of a 35 years old female with type IIb arm deformity

\section{DISCUSSION}

Brachioplasty has been widely applied to correct contour deformities of redundant arms using many surgical techniques had been described. Although it is an old procedure, however the percentage for brachioplasty has increased nowadays in proportion to the continuous increase in numbers of massiveweight loss patients [7].

To coop with increased demands for the procedure and raised patients' expectations; many refinements has been done and short-scar approach was proposed to decrease the associated complications as ugly long wide scar, sensory loss, distal lymphedema, hematomas, hypertrophic scars and beside all this and most distressing; bad aesthetic result.
Many variations of the short scar developed as short-scar approach with only a vertical incision in the axilla [8], L brachioplasty with an unremarkable scar across the axilla and chest wall [9] inaddition to many $\mathrm{W}, \mathrm{T}$ or $\mathrm{Z}$ axillary incisions patterns $[\mathbf{1 0 , 1 1 ]}$. However these modification was applicable in type I and IIa patients with proximal deformities only and could not address distal deformities [12].

The post-massive weight loss deformities that affect the arms are usually of great variability concerning the amount of skin redundancy and fat deposits which cannot be corrected by the traditional brachioplasty thus the combination of multiple surgical methods is a must. 
Goddio [13] described de-epithelialization of the posterior skin flap instead of excision; this led to no scarring problems however scar revision rates remained high. Using definite statistical analysis, our study did not find any statistically significant increase in complications when concomitant procedures were added to brachioplasty.

Liposuction is most commonly used as an adjunct to excisional brachioplasty; it was performed safely with very-good appealing results and complication rates very similar to those of patients who performed excision alone. It preserves lymphatics, decreases risk of injury to the sensory cutaneous nerves, very low possibility of basilic \& cephalic veins damage, minimizes blood loss, creates a discontinuous undermining that makes the skin resection easier and allows closure with minimal tension.

De Runz and others [14] performed medial brachioplasty accompanied with liposuction where they resected only the skin layer and preserved the framework of subcutaneous vessels and lymphatics to decrease overall complication rates however; 37 out of 66 patients had at least one complication with overall satisfaction being reported as excellent in twelve patients $(22.6 \%)$ and pleasing in the remaining 24 patients $(45.3 \%)$.

Nguyen and Rohrich [15] present a series of 21 patients who underwent contouring of the upperarm with liposuction-assisted posterior brachioplasty; all patients tolerated the procedure very well with only minimal (small wound dehiscence and a minor hypertrophy of the scar in one arm) with zero revisional surgeries were performed. Although these are so close to our results, they still used the long traditional scar and the candidates had type IIc and IIIc deformities.

Hill and colleagues [12] performed circumferential liposuction with a short-scar brachioplasty and found high patient and surgeon satisfaction and concluded that this approach maximizes results and minimizes incision length. However patients included in that study had moderate skin excess and lipodystrophy limited to the proximal $1 / 3$ or even up to $1 / 2$ of the upper extremity.

After invention of the VASER Lipo System, it offered a vital revolution in the treatment of excess fat as it was intended to advance liposuction procedures by improving safety and efficiency, reducing complications and physician fatigue, and allowing for faster patient recovery [16].

Many studies had proved its apparent clinical benefits [17-20] that's why in this recent study, we studied the effect of combined VASER liposuction with the short scar brachioplasty usage to correct post-massive weight loss cosmetic disfigurement of both arms in 14 patients with grade type IIb and IIIb deformities. We think that this is the first research to demonstrate statistically significant clinically improvements in patients having this high grade of redundancy with the lowest possible complications.

Alfredo et al., 2007 [17] reported improved body contour and concluded that VASER-assisted high-definition liposculpture is an appropiate approach to body contouring facilitating the superficial liposculpture to define the 3-dimensional surface musculature.

Zhang et al., [18] stated that the 3-dimensional liposculpture concept is based on the fact the thinner the skin is, the greater its retraction is. This proven ability of VASER had led us to apply it as an adjuvant with short-scar brachioplasty to increase the scope of the liposuction-assisted procedure to include patients with moderate skin laxity and fat excess along the entire arm and thus avoid the long visible scar with all of its complications.

Di Giuseppe [19] stated that VASER is a new technology with high standards of value and safety; thus burns, seroma, skin sloughing that were grave possible complications in previously used tools; are not actually matters of questions with the recently introduced technology. That facilitated bloodless removal of the unwanted fat and lead to small number of complications in our study.

This procedure is more time-consuming compared to the conventional liposuction because the added emulsification step, however this is not to be of great significance with the final aesthetic outcome being excellent in $92.9 \%$ of patients without any functional problem as a result of the adequate skin tightening in the distal $1 / 2$ of both arm and absence of any residual excess fat.

\section{Conclusion:}

Transaxillary VASER assisted brachioplasty is an easy and simple technique that offers a good result with the most possible minimal scarring.

\section{REFERENCES}

1- Zomerlei T.A., Neaman K.C., Armstrong S.D., et al.: Brachioplasty Outcomes: A Review of a Multipractice Cohort. Plastic \& Reconstructive Surgery, 131 (4): 883889, 2013.

2- Hurwitz D.J. and Jerrod K.: L-brachioplasty: An adaptable technique for moderate to severe excess skin and fat of the arms. Aesthet. Surg. J., 30: 620-629, 2010. 
3- Chia C.T., Theodorou S.J., Hoyos A.E., et al.: Radiofrequency-Assisted Liposuction Compared with Aggressive Superficial, Subdermal Liposuction of the Arms: A Bilateral Quantitative Comparison. Plast. Reconstr. Surg. Glob. Open., 3 (7): e459, 2015.

4- Cimino W.W.: VASER-assisted lipoplasty: Technology and technique. In: Shiffman M.A., Giuseppe A.D., eds. Liposuction: Principles and Practice. New York, NY: Springer. Berlin. Heidelberg, 239-244, 2006.

5- de Souza Pinto E.B.1., Abdala P.C., Maciel C.M., et al.: Liposuction and VASER. Clin. Plast. Surg. Jan., 33 (1): 107-15, vii, 2006.

6- Appelt E.A., Janis J.E. and Rohrich R.J.: An algorithmic approach to upper arm contouring. Plast. Reconstr. Surg., 118: 237-246, 2006.

7- Fischer J.P., Wes A.M., Serletti J.M., et al.: Complications in body contouring procedures: An analysis of 1,797 patients from the 2006-2010 ACS-NSQIP databases. Plast. Reconstr. Surg., 132: 1411-1420, 2013.

8- Reed L.S.: Brachioplasty with limited scar. Clin. Plast. Surg., 41: 753-763, 2014.

9- Hurwitz D.J. and Holland S.W.: The L brachioplasty: An innovative approach to correct excess tissue of the upper arm, axilla, and lateral chest. Plast. Reconstr. Surg., 117: 403-411, discussion. 412, 2006.

10- Juri J., Juri C. and Elias J.C.: Arm dermolipectomy with a quadrangular flap and "T" closure. Plast. Reconstr. Surg., 64: 521-525, 1979.

11- Borges A.F.: W-plastic dermolipectomy to correct "batwing" deformity. Ann. Plast. Surg., 9: 498-501, 1982.

12- Hill S., Small K.H., Pezeshk R.A., et al.: Liposuction-
Assisted Short-Scar Brachioplasty: Technical Highlights. Plastic \& Reconstructive Surgery, 138 (3): 447e-450e, 2016.

13- Goddio A.S.: A new technique for brachioplasty. Plast. Reconstr. Surg., 84: 85-91, 1987.

14- de Runz A., Colson T., Minetti C., et al.: LiposuctionAssisted Medial Brachioplasty after Massive Weight Loss: An Efficient Procedure with a High Functional Benefit. Plast. Reconstr. Surg., 135: 74e, 2015.

15- Nguyen A.T. and Rohrich R.J.: Liposuction-assisted posterior brachioplasty: Technical refinements in upper arm contouring. Plast. Reconstr. Surg., 126: 1365-1369, 2010.

16- Jewell M.L., Fodor P.B., de Souza Pinto E.B. and Al Shammari M.A.: Clinical application of VASER-assisted lipoplasty: A pilot case study. Aesthetic. Surg. J., 22: 131$146,2002$.

17- Hoyos A.E. and Millard J.A.: VASER-assisted highdefinition liposculpture. Aesthet. Surg. J., 27 (6): 594604, 2007.

18- Zhang Y.X.1., Lazzeri D.1., Grassetti L., et al.: Threedimensional Superficial Liposculpture of the Hips, Flank, and Thighs. Plast Reconstr Surg Glob Open. Feb., 6; 3 (1): e291, 2015.

19- Di Giuseppe A.: "Ultrasound-assisted lipoplasty for face contouring with VASER." Liposuction. Springer. Berlin. Heidelberg, 245-253, 2006.

20- Nagy M.W. and Vanek P.F. J.r.: A multicenter, prospective, randomized, single-blind, controlled clinical trial comparing VASER-assisted Lipoplasty and suction-assisted Lipoplasty. Plast. Reconstr. Surg. Apr., 129 (4): 681e-9e, 2010. 